\title{
Forum
}

doi: $10.1017 / \mathrm{S} 0373463310000366$

\section{The Paradigm and the Paradox of Perfect Pilotage}

\author{
Captain Richard J Wild \\ (Senior Pilot and Examining Pilot, Harwich Haven Authority) \\ (Email: richardjwild@gmail.com)
}

It is an unpalatable truth but by and large the success or failure of navigating a merchant ship in confined pilotage waters rests largely with a single individual - the pilot. Should the pilot make an error of judgement (to err is human) then his/her position as a single but vital weak link can be rapidly and cruelly exposed. Bridge teams and pilots need to improve their mutual understanding and expectations. Passage planning needs more consideration and more timely communication. The Master Pilot Exchange (MPX) needs to change from a tick-box exercise to something more meaningful, more substantive and above all, to represent a plan that can be executed and monitored.

\section{KEY WORDS \\ 1. Bridge Team Functions. 2. Communication. 3. Electronic MPX.}

1. INTRODUCTION. Even bridge teams who have undergone bridge resource management training often do not work with the pilot, apart from what could be summed up as administrative functions such as instructing the crew at the various outstations on the ship. There are exceptions to this, particularly when the bridge team has collectively trained as a team. Although individuals should be interchangeable within the team as crew join and leave the vessel, a well-drilled team work better together if they stay together. A good example of this is a cruise ship. On boarding such a vessel, the pilot is often welcomed into the bridge team, is given a full brief and individual responsibilities are clarified. However, this is the exception rather than the rule.

The challenge is therefore not to just install more technology onto a ship, or to simply train officers on how to use this equipment. The solution lies between the two. Maritime Resource Management (MRM) is a training program that has been developed by The Swedish Club Academy. It is a continuation of bridge team or Bridge Resource Management (BRM) training and it goes a long way to addressing the problem. The main assumption is that all the skills required to navigate the ship safely already exist. This type of training should be near the top of any Continuous Professional Development (CPD) schedule undertaken by pilots and Masters. The advantage of the Master undertaking MRM is that he can 'spread the gospel' when he returns to his ship and lead his team, which includes the pilot. Unlike BRM, much 
of the emphasis of MRM is directed towards two individuals; the Master and the pilot (or conning officer). The course is thought provoking and delivers a subtle but very powerful message.

The key is to be able to slot the pilot into the bridge team, or for the ship's own conning-officer to assume that position and for the remainder of the team to support him by actively monitoring the conning orders. This means more than checking that the helmsman puts the rudder the correct way when an order is given. It means that for example, set/leeway is applied in the right direction by the pilot; it means that if the pilot states that he intends entering the harbour or a major turn at 8 knots, the ship is not doing 12 knots because the pilot has been distracted and has not slowed down in time. In the first instance, the scene must be set correctly to encourage challenge and reply responses to conning orders. And communication and orders must follow a closed-loop pattern.

All that is now required is an agreed passage plan.

2. THE PASSAGE PLAN. The intended route for a particular passage can be in the pilot's head but normally the necessary route is obvious or reasonably selfevident because the ship must follow a charted channel or river. The precise track may be subject to change, and the pilot must be able to adapt the agreed passage plan if circumstances beyond his control dictate that this must happen. Berth availability may alter over a change of tide and so the pilot might favour a different side or position in a channel or river. Conflicting traffic may cause the pilot to alter course early or late and again adopt a different position in a channel. In other words there are innumerable reasons why the passage plan carefully drawn up by the ship's navigating officer, particularly if it is a centre-line route simply reversed for the opposing voyage, is not the same as the pilot's plan. So it is best to view a passage plan as a basis for controlled change, and to be prepared to use all the available safe water.

The most demanding and exacting time to navigate a ship close to the limits of its operating envelope is when executing a critical course alteration. The limits of the operating envelope are for example, low under keel clearance (UKC), narrow channel/fairway, high wind velocity and strong currents. This is exacerbated when in poor visibility and all this can be summed up as navigating in marginal conditions.

It is easy to pre-plan straight line tracks; any competent OOW can do this and subsequently monitor the actions of an embarked pilot. However, it is turns or significant course alterations, particularly in reduced visibility that can result in a ship deviating from the desired track with disastrous consequences. A good rule of thumb in pilotage is that 10 seconds loss of concentration can mean an untidy job whereas 20 seconds loss of concentration is likely to be catastrophic.

It is possible to use a variety of radar techniques such as off-setting the centre and driving the ship around a pre-calculated arc to maintain the correct track. However, these skills do not always readily transfer from one location to the next; there may not be a suitably located radar conspicuous object or the rise and fall of tide might mean that it is impossible to identify the true radar image from the chart and calculate the correct track. Furthermore to expect the OOW or navigating officer to precalculate all the wheel-over positions with all the aforementioned variables and the 
bridge team to monitor all this is a big challenge. But, all of this plus the knowledge of rate-of-turn can make a difference - up to a point.

The next problem is that the ship's manoeuvring data is valid for the conditions when it was done. Such data is normally obtained while the ship is in yard-ownership and often the required additional data is extrapolated from that obtained from the light-ship, relatively high under-keel clearance trials. In other words, when the ship is fully loaded and the UKC is say just $10 \%$ of the draught, the published turning data may be speculative. The actual turning radius could be double that indicated on the Bridge Card. Advance/transfer details for a $90^{\circ}$ and $180^{\circ}$ turn as obtained on sea trials are important to the OOW in open water but of less use to the pilot operating at the extremes of the navigable envelope for the ship. When the navigating officer is drawing up his plans he can make an educated guess as to the track the pilot may take on a significant turn. But what about the in/out speed of this turn and the required RoT? Furthermore, how should it be monitored? If the ship has a rate-of-turn indicator this becomes an invaluable instrument and in fog, on a large ship it is essential. However, without prior calculation of speed into the turn, speed loss during the turn and average speed in the turn, it would be difficult for the navigating officer to predetermine what the RoT should be. Who, in dense fog, is going to challenge the pilot? Even if suitable mid-turn heading checks can be identified from the chart, in poor visibility it might not be possible to use them.

3. SHORE ASSISTANCE. Shore-based pilotage (SBP) or Navigational Assistance (NAS) exist and offer different services. SBP is remote pilotage of the ship and is normally conducted by a pilot. Some countries, notably the United Kingdom, have determined that pilotage is conducted from the bridge of a ship. NAS is an advisory information service confined to positional support and advice on a track to make good; the ship must determine what course to steer. Some might take the view that such concepts (and they are two different things) should have a greater role in the navigation of shipping.

A recent study, conducted in Swedish waters (Bruno \& Lützhöft, (2009)), suggests when the pilot is used in a support role he/she is wholly or partly superfluous today. This may be so where the ship is a regular caller to a particular port and the same crew are regularly assigned to the ship. However, the reality is that both ships and their crews are regularly re-deployed, particularly in a fast changing economic climate.

However, shore assistance in either format can be of significant assistance when a critical turn is being made and provides a very useful backup to the pilot and bridge team. Ideally this should provide positional information and a commentary to include buoy/mark transits and other traffic. Positional information could be given in a number of ways such as range/bearing or passing marks. However, practical advice relative to the channel centre line or channel edge, using terms such as a quarter, a third or a half are easy to mentally interpret whereas range/bearing information from a buoy/mark is not so easy to visualise. Any advice or information given to the ship should be result orientated.

A flaw of SBP is that total control of a ship from a remote station cannot be achieved unless the controlling pilot has to hand all the data, both visual and instrumental, that is available on the ship. Of course, with the aid of cameras and very 
fast data links, this could be made possible, but, and it is a big but, no two acts of pilotage, particularly when operating at the edge of the envelope, are the same. The ship will behave differently, and therefore turn slower or faster at the critical points with different environmental conditions and at different drafts.

So although the paradigm is flawed, some aspects of SBP could bear fruit. It may have relevance in the channel phase of a voyage where a pilot is taken, but has no relevance in the harbour or berthing phase. The idea of slot management has been aired; it is a concept borrowed from the air-world. This could be a positive step but only in the open sea part of a voyage or possibly the approach phase to a pinch point such as a headland that must be rounded by numerous ships or when approaching a pilot station. A Traffic Separation Scheme may exist in either of these situations.

4. SIMULATION AND EXPERIENCE. The pilot can gain considerable benefit from port-specific simulators when regular visiting ships are accurately modelled. An example of this is HR Wallingford in Oxfordshire, which has done a considerable amount of research and simulation for Harwich Haven Authority. The simulators were not designed for bridge team training but more for pilots and ship's masters to practice manoeuvres with low UKC, high winds and strong currents on a variety of ships. The $335 \mathrm{~m}$ LOA Continent class ship of approximately 8500 TEU has been very accurately modelled using a blend of theoretical calculations and practical observations. Emergency scenarios such as a tug line parting or bow thrusters failure can be practised.

The point here is that however well drilled the bridge team is, and regardless of how much work has gone into the berth-to-berth passage plan by the ship's navigating officer, the extra and possibly vital knowledge that the pilot brings, both from experience and the simulator is largely in his head; that is why he is there.

\section{THE MASTER PILOT EXCHANGE AND ELECTRONIC PASS-} AGE PLANS. The pilots in Brisbane, Australia are reported (Heath \& Drouin, 2009) as having introduced a radical change in the way they treat the bridge team of a ship arriving off the port. The passage plan is jointly agreed and charts, both paper and electronic, are adjusted to reflect this. Indeed the ship does not proceed inwards (or presumably leave the berth) until the ship's and the pilot's passage plans are identical. This would seem to be the holy grail of pilotage.

One immediate problem in congested European and Asian waters is does the arriving ship have the space and time to stop and drift or slow steam whilst this procedure is carried out? Possibly not, and certainly not in poor visibility, if there is other traffic close by. One way to solve this problem is to move pilot boarding grounds further seaward into safer waters but this could mean that boarding becomes more difficult in inclement weather so it is not an ideal one-cap-fits-all solution. Another issue is does the ship have the required charts and passage plan in the first instance? Mostly yes, but sometimes, no. If there are no charts, there will not be a passage plan on the ship.

Even if the ship is fitted with ECDIS, there is no guarantee that the largest scale charts (and up-to-date) for the port will be available.

A potential solution which merits further examination is the electronic exchange of pilotage plans initiated by the pilotage provider or harbour authority. Such a plan 
Table 1. The Electronic MPX.

1. Pilot is provided with a comprehensive analysis of the proposed voyage without having to spend time finding information.

2. VTS or data centre completes ship details (including pilot notes) and voyage summary.

3. VTS or data centre completes administrative elements (launch and other transport details for example)

4. Permits automatic completion of calculations (windage and heel)

5. Electronic archiving possible.

6. Certain fields are protected (i.e. berth-box and channel depths) and can only be altered by the relevant authority. This ensures that VTS and pilots have same parameters.
1. If wholly electronic, the Master/ Bridge Team can only view the proposed voyage on a screen.

2. If the MPX is emailed to the ship it may not be delivered to the Bridge or printed off.

3. A paper MPX will need to be completed from scratch if there is a failure of the electronics.

could be either wholly electronic or a hybrid designed to be printed-off onboard the ship. Some ports, for example Sydney and Port Philips in Australia, have made animated versions of their standard passage plans available on their respective websites. These are very useful and, assuming the ship is able to download the files in good time, they enable the ship's navigating officer to prepare the ship's charts. Further information, such as tug deployment and any calculations, must still be discussed onboard.

The wholly electronic version is likely to be a spreadsheet solution which will enable some calculations to be performed automatically. These could include calculations for $\mathrm{UKC}$, windage tonnes, increase of draught with heel and possibly a waypoint-timing sheet, cross-referencing to critical UKC points if pertinent. Static or non-dynamic data could be automatically entered from a database maintained by the pilotage authority or even off the internet. This would include limiting depths and the principal dimensions of the ship. The advantages/disadvantages of the Electronic MPX are seen in Table 1.

A hybrid solution could offer a chartlet indicating the intended route and the proposed manoeuvre/berth plan, in addition to spreadsheet calculations. Inclusion of a berthing/un-berthing plan is important and this was identified into the MAIB report on the Sichem Melbourne. While the hybrid version could be viewed on a screen it might encompass more than one page and so a hard copy would be easier to see. The advantages/disadvantages of the hybrid MPX are seen in Table 2.

If the proposed passage plan is received on the ship before the pilot embarks, the ship can ensure that at least the intended track is one and the same.

6. PORTABLE PILOT UNITS (PPU) AND PERSONAL DIGITAL ASSISTANTS (PDA). Either of the proposed electronic passage plans can be used in tandem with a PDA or palmtop device. This will enable the pilot to refine calculations whenever required. The pilot can also receive information from a VTS centre, either by accessing an extranet site or data can be pushed to the PDA. If the VTS centre or pilot base station maintains a vessel database, this can be readily 
Table 2. The hybrid paper/electronic MPX.

1. VTS or data centre completes all the static elements such as ship's particulars and pilot notes.

2. Un/Berthing manoeuvre can be discussed using sketch.

3. Proposed route can be readily indicated on a schematic diagram and the ship can note the waypoints and put the route into the ECDIS for example.
1. Archiving only by manual filing or scanning for electronic storage of paper copies.

2. Managing any changes to the dynamic elements (e.g. windage height or draft).

3. Concept reliant on the MPX being delivered to the pilot at all the out-stations.

4. A paper MPX will need to be completed from scratch if there is a failure of the electronics.

transmitted to the pilot. Furthermore, Pilot-to-Pilot notes about vessels such as any unusual handling characteristics can be included within the ship data. These can then be sent to the pilot along with the LOA, beam and propulsion for example. Using a PDA is a much cheaper alternative than an expensive ruggedized laptop or Portable Pilot Unit (PPU).

The PPU concept has advantages and disadvantages. The pilot is able to access independent positional information. This could be superior to information onboard the ship. The VTS traffic image can be overlaid onto the PPU and this can be very useful for timing own-ship arrival at a pinch point and anti-collision functions. The PPU can provide accurate vector and distance information at the berthing/ un-berthing stage. The path predictor track is also very useful, but it may not be as accurate as the information on the ship's ECDIS. But the PPU is useful if it is taken to the bridge wing.

One negative aspect of the PPU is that due to the size of the display, it can only be viewed by one or two individuals simultaneously. It could be said that the pilot is now outside the bridge team because he is accessing and interpreting information that others are unable to view. There are also issues as to whether the harbour authorities' own survey data should be displayed or suppressed.

However, electronic charts and portable pilot units make considerable advances in the execution and monitoring phase of the voyage. This is particularly important in cases where the parameters are small and the ship is being operated to the limits of the navigable envelope. As ships have become larger, situational awareness has reduced; on a ship of say $60 \mathrm{~m}$ beam it is easy to become disorientated if the pilot or conning officer moves from one side of the bridge to the other. It is much better to remain at the principal conning position (which may be off-centred), even if channel buoys cannot be seen while swinging the ship and even transiting a narrow channel. The bridge team can make good use of an ECDIS system by observing where the ship is and where the predicted track indicates the ship will be in the future.

Returning to the critical course alteration the ship must negotiate, a path-predictor overlaid onto a vector or raster chart would seem to be the panacea required and to offer a solution. However such a feature on an ECDIS (vector chart only) does not tell the complete story. When the helm is put over and the turn started, the path predictor will indicate where the ship will be in the future taking into account the rate of turn, the speed over the ground and the drift angle. 
The calculation of the drift angle is very important. Ideally this should be done by a twin-axis bottom tracking Doppler log which will provide a real-time and instantaneous indication of where the ship is going as opposed to where it is heading. Should this information be provided by GPS, GLONASS or Galileo, the accuracy will depend on any position damping set within the unit. The projected path of the ship will lag behind (latency) what would be displayed by the Doppler log, and more importantly, not reflect what an experienced pilot could observe visually.

Augmentation systems, which include differential GPS, WAAS (Wide Area Augmentation System) and EGNOS (European Geostationary Navigation Overlay Service), offer increased integrity. They will provide better accuracy when compared with non-differential GNSS. However, in reduced visibility a significant turn becomes an instrument only challenge and the bridge team has to use everything at its disposal, which will include the unquantifiable element of the pilot's experience. There can be conflict because the margins are very small and there is very little time to move from passive monitoring of a turn to challenging the pilot and then taking the con from $\operatorname{him} /$ her.

When a pilot approaches a significant turn, he may want to position the ship on the outside of the approach leg, always allowing for current and leeway. This will enable the pilot to warm the turn i.e. start the turn early without committing everything to the turn. Full helm and a significant increase in engine revolutions/propeller pitch can be held in abeyance and used if needed to increase the rate of turn.

Once the plan has been agreed, taking into account the nuances such as described above, the next phases - execution and monitoring take place simultaneously. It may seem an obvious statement, but the pilot executes the plan and the bridge team monitor his actions; this is very important. It is the bridge team who can determine the success or failure of the voyage because simply put, the buck stops with them. If the pilot commences a turn too late, or too early, or allows the ship to proceed too fast, the bridge team must rapidly advise him or if necessary intervene directly.

\section{BRIDGE TEAM FUNCTIONS AND RESOURCE MANAGE-}

MENT. The concept of the bridge team is not new but numerous failings are still identified and recorded today. Training courses, procedures and standing orders have been written, re-drafted and re-written numerous times over the last 40 years by shipping companies, Masters and training establishments. There is a plethora of advice as to what the bridge team must do, but a code is needed to set out how it is to be done. The problem is not a lack of knowledge, but more a failure to understand how the bridge should be run and to train people to undertake each role so that they can move from one ship to another and know what is required of them. In short, technical advances have made pilotage more precise and easier to monitor but bridge management has not kept pace.

Minimum-manning standards are laid down for all ships but the actual range of bridge team possibilities is limited. Generally, the smallest of ships e.g. a coastal bulk carrier, could have a Master, one Mate plus a lookout. This bridge team has to undertake the same functions as the largest cruise ships which could have four or even five deck officers available and several lookouts.

The draft amendment to SOLAS Regulation V/19 determines when ships on international voyages will be required to have ECDIS fitted. The smallest bulk carriers 
Table 3. Bridge team functions according to team numbers.

\begin{tabular}{|c|c|c|c|c|}
\hline \multirow[b]{2}{*}{$\begin{aligned} \mathrm{M} & =\text { Master. } \mathrm{DO}=\text { Deck Officer } \\
\mathrm{L} & =\text { Lookout } \mathrm{H}=\text { Helmsman }\end{aligned}$} & \multicolumn{4}{|c|}{ Ships Manning in Confined/Congested/Pilotage Waters } \\
\hline & $\begin{array}{l}\mathrm{M} \& 3 \mathrm{DO} \& \\
>1 \mathrm{~L} \&>1 \mathrm{H}\end{array}$ & $\begin{array}{c}\mathrm{M} \& 2 \mathrm{DO} \& \\
\mathrm{~L}+\mathrm{H}\end{array}$ & $\begin{array}{l}\text { M \& } 1 \text { DO \& } \\
\text { L \& H }\end{array}$ & \\
\hline In Command & $\mathrm{M}$ or designate & $\mathrm{M}$ or designate & M & \\
\hline Conning Officer (Note 1) & Pilot or Ship Off* & Pilot or Ship Off** & Pilot or M & \\
\hline Position Monitoring** (Note 2) & DO1 (ECDIS) & DO1 (ECDIS) & $\mathrm{M}$ or DO & $\begin{array}{l}\text { Officer Not } \\
\text { Conning }\end{array}$ \\
\hline Anti-Collision (Note 2) & DO2 & DO2 & $\mathrm{M}$ or $\mathrm{DO}$ & $\begin{array}{c}\text { Officer Not } \\
\text { Conning }\end{array}$ \\
\hline External Communication & $\mathrm{M} /$ Pilot/DO & M/Pilot/DO & $\mathrm{M} /$ Pilot/DO & \\
\hline Internal Communication & DO3 & $\mathrm{M} / \mathrm{DO}$ & $\mathrm{M} / \mathrm{DO}$ & \\
\hline Lookouts & $\mathrm{L} 1 / \mathrm{L} 2$ & L1 & L1 & \\
\hline Helmsman & $\mathrm{H} 1 / \mathrm{H} 2$ & $\mathrm{H} 1$ & H1 & \\
\hline
\end{tabular}

* The Ship's conning officer could be the Master or an alternative.

** To include depth monitoring.

NOTES:

1. The conning officer must have access to an ECDIS work station and is likely to use a chart/radar display as the primary aid to navigation where fitted.

2. Also called Officer Not Conning. The ability to designate separate position monitoring and anti collision watch keepers is largely dependent on the number of work stations that are available.

(as described above) of less than 3000 gross tonnes will not be captured but eventually all tankers and cargo ships over 3000 gross tonnes, and all passenger ships over 500 gross tonnes will be required to have ECDIS fitted. The human resources on the bridge of a ship need to use all the physical resources at their disposal, and this will include ECDIS, to the best advantage. In turn the human resources need to interact with each other in a calm, considered and constant manner. Table 3 is an attempt to specify the roles that all the bridge team members must fulfil for a range of ship complements.

8. CONCLUSIONS. There is a clear need to re-emphasise the roles and the functions on the bridge of a ship for the most hazardous phases of a voyage. The technical knowledge required to fulfil each role should be within the capabilities of any OOW, with the possible exception of ECDIS which often requires more in-depth brand-training (which can be undertaken onboard the ship) rather than generic training. Cultural and hierarchal differences can be an issue and these need to be put aside. Training may be required in this area.

Technology can be used to significantly increase the safety of a ship navigating near to the limit of the operating envelope. It is not so much the case that more complicated solutions need to be found, but information that is already available needs to be communicated in a more efficient manner. The more esoteric information that may exist in the pilot's mind needs to be communicated and shared.

Greater emphasis is needed on the more critical aspects. For example, while the ship needs to know approximately where and when the tug will be secured (so that the crew can be called) the bridge team needs to know and understand what tug power is available (and what is recommended), how the tug will be deployed and what manoeuvre is proposed. Critical turns may need some discussion; will the wind/current 
assist or hinder the turn? Where is the ship's wheel-over position and how does this compare to the pilot's? What rate of turn does the pilot believe will be required to make the turn? Are any mid-turn check bearings or transits available?

The pilot should give broad indications of what speed he intends or anticipates at various stages of the voyage, particularly when approaching critical turns and prior to swinging. The bridge team then have something to monitor rather than just thinking he's going too fast. Similarly, the expected under keel clearance needs to be shared and closely monitored; the nearest danger to a ship is normally underneath the ship.

The pilot can use the bridge team in a far more active manner if he simply informs them at the passage planning stage, or even as the voyage progresses, of his future intentions. The pilot needs to be able to gauge whether he can deliver a snap-shot of the whole voyage in one go, or whether he should share his intentions in bite-sized chunks as the ship proceeds so that the Master is not overwhelmed by information relating to an event that will happen several hours later.

It is incumbent on the pilot to invite challenges to the orders he gives whilst conning the ship. This could be referred to as setting the scene for dialogue. It creates a positive and proactive atmosphere. In turn, the Master needs to encourage his bridge team to play a more active role. This is a very positive step forward.

Master-Pilot Check Lists exist which require the pilot to sign a box to indicate that he has been informed of his Emergency Muster Station and Lifeboat. Documents with this level of information exchange should be scrapped. Hopefully, the voyage will be successful and the pilot will never need to know this information. This type of exchange needs to be changed to something fit-for-purpose in the 21 st century.

\section{ACKNOWLEDGEMENTS}

The Swedish Club Academy, Gothenburg, Sweden.

\section{REFERENCES}

Bruno, \& Lützhöft. (2009). Shore-Based Pilotage: Pilot or Autopilot? Piloting as a Control Problem. The Journal of Navigation, 62, 427-437.

Heath, \& Drouin. (2009, Oct). The Pilotage Paradigm. Nautical Institute Seaways, 12-14. 